\title{
Texture and magnetic anisotropy of polycrystalline extruded rods of $\mathrm{Ni}-\mathrm{Mn}-\mathrm{Ga}$ alloys
}

\author{
H. Morawiec ${ }^{\mathrm{a}, 1}$, J. Lelątko ${ }^{1}$, T. Goryczka ${ }^{1}$, K. Prusik $^{1}$, St. Piechota ${ }^{2}$ \\ ${ }^{1}$ Institute of Materials Science - University of Silesia, Katowice, Poland \\ ${ }^{2}$ Institute of Physics - PAS, Warszawa, Poland
}

\begin{abstract}
It is well known that a relatively high magnetic anisotropy and magnetic field can induce strain in the polycrystalline Ni-M-Ga alloy, especially, in the preferred $<001>$ orientation. A significant technological improvement may be achieved by producing textured rods with axial orientation. This was realized by rods extrusion at high temperature with a proper reduction rate. The paper concerns the comparison of texture, magnetization and magneto-crystalline anisotropy constant for samples cut out from the columnar grain zone and cut from extruded rods.
\end{abstract}

\section{Introduction}

The main theoretical principles for selection ferromagnetic shape memory alloys based on Heusler compounds are generally known and experimentally proved for single crystals of Ni-Mn-Ga alloys [1,2]. The summary of the latest achievements in this field has been given in [3,4]. Extension of these results to polycrystalline materials would significantly increase the application capabilities of this class of materials. It is also understood that the magnetic field induced strain (MFIS) of the polycrystalline alloys is remarkably smaller than that of single crystals because of the randomly oriented grains and twin variants in martensite. One of important factor which controls the MFIS effect is the magneto-crystalline anisotropy of the martensite with $\mathrm{c} / \mathrm{a}<1$. A crystallographic texture of the polycrystalline alloy can meaningly improve this effect because the preferred orientation is the $<001>$ direction which is the easy magnetization direction. The trials of obtaining the textured polycrystalline Ni-Mn-Ga alloys include the directional solidification [5], melt spun ribbon processing [6] and directional deformation [7-9].

The aim of this work was to introduce into the studied alloys the axial $<001>$ texture by rod extrusion process and to determine the effect of the privileged orientation on the magnetocrystalline anisotropy constant.

\section{Experimental procedure}

The studied two batches of polycrystalline alloys were prepared by melting in an induction furnace under argon atmosphere using $99.99 \%$ pure elements. The chemical composition was determined by the EDS method. The $\mathrm{M}_{\mathrm{s}}$ temperatures, structure and characteristic parameters of the studied alloys are given in Table 1 . The round ingots of $20 \mathrm{~mm}$ diameter were homogenized at $1050^{\circ} \mathrm{C}$ for 2 hours and extruded into rods of $10 \mathrm{~mm}$ diameter with the reduction rate of $75 \%$. The die was heated to be sure that the extrusion process was carried out in the B2 phase state. The specimens were cut in a rectangular shape along the $<001>$ direction of the columnar grains from the round shape ingots and extruded rods. The texture was studied by EBSD and X-ray diffraction using $\{001\},\{110\}$ and $\{111\}$ pole figures. The EBSD measurements were carried out with the use of the scanning electron microscope (JEOL JSM 6480) equipped with Nordlys II camera supported by a computer with the HKL Channel 5 system. In order to collect the grain orientation from large surfaces the experiments were carried out at magnification of $100 \mathrm{x}$ and the grid step size of $4 \mu \mathrm{m}$. Every orientation map consisted of 4 mapping jobs.

\footnotetext{
a e-mail: henryk.morawiecaus.edu.pl
} 


\section{Results and discussion}

The annealing of the ingots at $1050^{\circ} \mathrm{C}$ caused the radial growth of the columnar grain perpendicular to the ingot axis. This produced the preferred $<001>$ orientation. Figure 1 shows the macroscopic view of the transient ingot zone (Fig. 1a) and the microstructure which depicts the flow and rotation of the grains along the extrusion axis (Fig. 1b). The martensitic plates with high twin density in alloy M3 were observed within the grains.
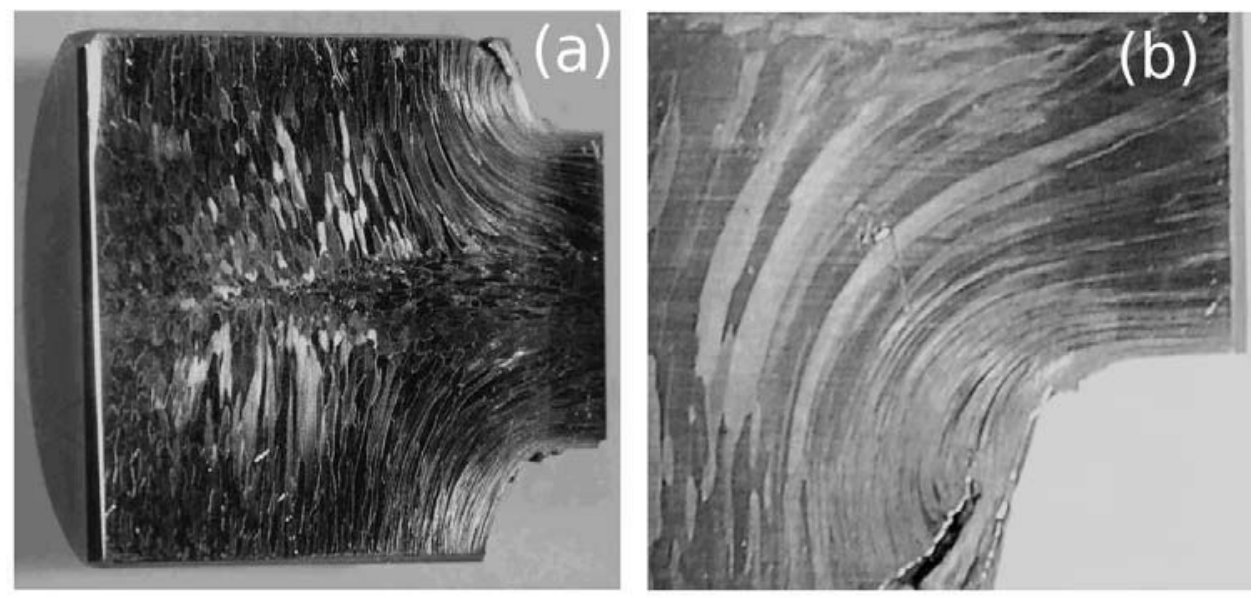

Fig. 1. Macro (a) - and microstructure (b) of the transient ingot - rod zone

X-ray diffraction as well as by TEM revealed that all the studied alloys show the five-layered $10 \mathrm{M}$ structure of the martensite. Fig. 2. shows the microstructure (Fig. 2a) and electron diffraction pattern of 10M martensite for M3 alloy(Fig. 2b).
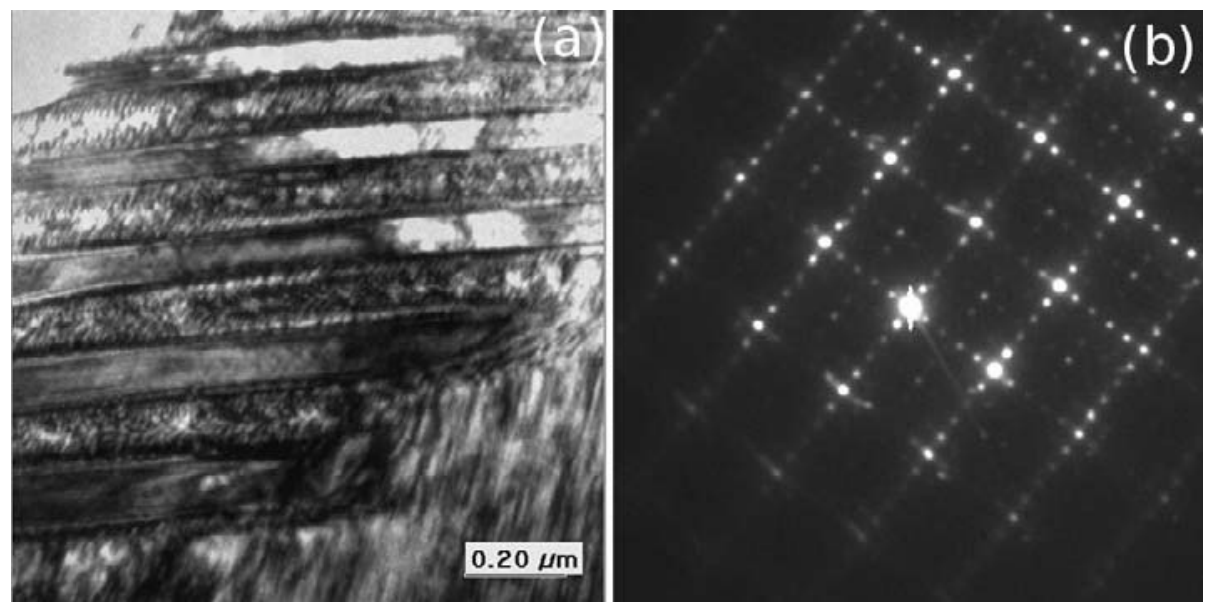

Fig. 2. Morphology of martensite (a) and diffraction pattern of 5 layered structure in alloy M3 (b)

The aim of the studies was to compare the texture, magnetization and magnetocrystalline anisotropy constant for samples containing columnar grain zone and these cut from the extruded rods. The pole figures obtained from the longitudinal cross section for a sample cut out of the columnar grains of M3 alloy is shown in Fig. 3. The pole figures confirm the $<001>$ texture. The distribution of the orientations in the pole figures show that the specimen is a strongly textured polycrystalline material.

The pole figures of the extruded rod from the M3 alloy taken also from the longitudinal cross section (Fig. 3b) shows the scattered grains oriented about the $<001>$ direction. Computer processing of the scattered data allows to contour the pole figures and thus reveals the preferred orientation. The interpretation of the texture in the tetragonal martensite with $\mathrm{c} / \mathrm{a}=0.94$ was based on the assumption that within $2 \%$ of accuracy it may be related to the standard projection for the cubic system. The axial $<001>$ texture for both kind of specimens cut from columnar grains of the ingot and for the extruded rods is very similar. 


\section{(a) columnar grains}
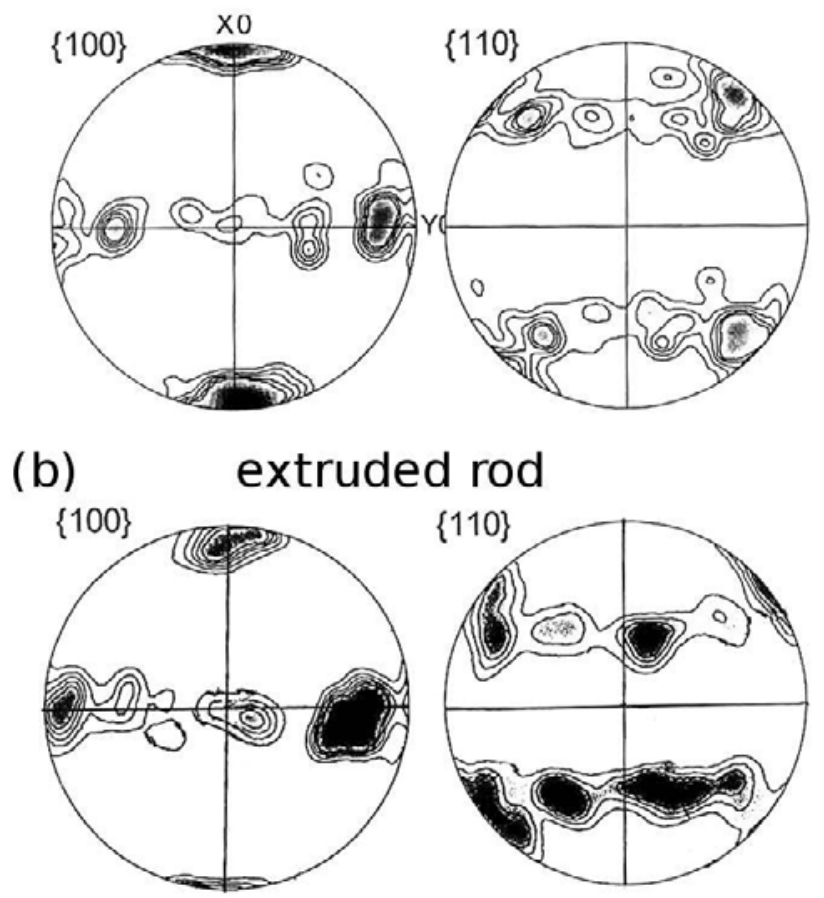

Fig. 3. EBSD computer processed pole figures of the axial texture for columnar grains (a) and extruded rod (b)

The magnetization curves for both specimens with columnar grain texture and the extruded rod show 3 curves: the $\mathrm{c}$ curve for the longitudinal direction which corresponds to the $<001>$ direction and the $\mathrm{a}$ and $\mathrm{b}$ are related to the transverse direction of the rectangular shape of the sample. The magnetic field corresponding to the saturation of magnetization varied between 0.9 and $1.4 \mathrm{~T}$ and the values of the magnetization saturation $\mathrm{M}_{\mathrm{s}}$ changed from 50 to $65 \mathrm{emu} / \mathrm{g}$. The macroscopic model of the magnetic field induced strain assumes that the magnetic shear stress $\tau_{\mathrm{m}}$ must exceed the yield stress for the twin boundary motion $\tau_{\mathrm{y}}$. This condition has been stated generally [10-12] as:

$$
\tau_{\text {aag }}=\frac{K_{u}}{\gamma_{0}}>
$$

where: $K_{u}$ is the uniaxial magnetocrystalline anisotropy constant and $\gamma_{0}$ is shear strain involved in the process. The value of $\mathrm{K}_{\mathrm{u}}$ is calculated from magnetization measurements basing on the relation:

$$
\mu M_{S} H=: K_{u}
$$

where $\mu_{0} M$ is the saturation magnetization and $\mathrm{H}$ is the value of the magnetic field related to $M_{s}$.

The shear strain $\gamma_{0}$ is calculated from the tetragonal lattice distortion of $10 \mathrm{M}$ martensite. The used relation is as follows:

$$
\left.\gamma=1-c / a)^{2}\right] /(1-/ a)
$$

for the five layered martensite $\gamma_{0}=0.12$. It is well known that for the field induced twin boundary motion to occur, application of the magnetic field must result in the mechanical shear stress on the atoms on the twin plane so that this plane moves into the unstable variant.

To lower the twin yield stress the mechanical training was carried out on the rectangular samples along three axes with different stress [13]. The obtained results are satisfying only for the samples of the extruded rods of alloy M6. The obtained value is $\tau_{\mathrm{y}}=2.5 \mathrm{MPa}$. All the calculated and measured: $\tau_{\mathrm{y}}, \mathrm{K}_{\mathrm{u}}$ and $\tau_{\mathrm{y}}$ which characterize the ferromagnetic shape memory alloys are given in Table 1. 
Table 1. Chemical composition and characteristic parameters for the studied Ni-Mn-Ga alloys

\begin{tabular}{|c|c|c|c|c|c|c|c|c|c|c|}
\hline Alloy & $\begin{array}{c}\mathrm{Ni} \\
{[\mathrm{at} \%]}\end{array}$ & $\begin{array}{c}\mathrm{Mn} \\
{[\mathrm{at} \%]}\end{array}$ & $\begin{array}{c}\mathrm{Ga} \\
{[\mathrm{at} \%]}\end{array}$ & $\begin{array}{l}\mathrm{M}_{\mathrm{s}} \\
{[\mathrm{K}]}\end{array}$ & Structure & Texture & $\underset{\left[\mathrm{J} / \mathrm{m}^{3} \times 10^{5}\right]}{\mathrm{K}_{\mathrm{u}}}$ & $\begin{array}{c}\tau_{\operatorname{mag}=}=K_{u} / \gamma_{0} \\
{\left[\mathrm{~J} / \mathrm{m}^{3} \times 10^{5}\right]}\end{array}$ & $\begin{array}{c}\tau_{m a g} \\
{[\mathrm{MPa}]}\end{array}$ & $\begin{array}{c}\tau_{y} \\
{[\mathrm{MPa}]}\end{array}$ \\
\hline \multirow[t]{2}{*}{ M3 } & \multirow[t]{2}{*}{49.13} & \multirow[t]{2}{*}{27.48} & \multirow[t]{2}{*}{23.39} & \multirow[t]{2}{*}{328} & \multirow[t]{2}{*}{$10 \mathrm{M}$} & $\begin{array}{c}\text { Columnar } \\
\text { oriented } \\
\text { grains }\end{array}$ & 1.6 & 12.92 & 2.56 & 10 \\
\hline & & & & & & $\begin{array}{l}\text { Axial } \\
\text { texture } \\
\text { of rods }\end{array}$ & 1.62 & 13.02 & 2.58 & 10 \\
\hline \multirow[t]{2}{*}{ M6 } & \multirow[t]{2}{*}{51.5} & \multirow[t]{2}{*}{28.8} & \multirow[t]{2}{*}{19.8} & \multirow[t]{2}{*}{366} & \multirow[t]{2}{*}{$10 \mathrm{M}$} & $\begin{array}{l}\text { Columnar } \\
\text { oriented } \\
\text { grains }\end{array}$ & 1.53 & 12.44 & 2.47 & 25 \\
\hline & & & & & & $\begin{array}{c}\text { Axial } \\
\text { texture of } \\
\text { rods }\end{array}$ & 1.76 & 14.19 & 2.81 & 2.5 \\
\hline
\end{tabular}

More detailed studies of the extruded rods have shown the inhomogenities of the axis texture both on the cross section as well along the rods. Additionally orientation component of $<110>$ axis have been stated particularly in the centre and initial part of the extruded rods.

\section{Conclusion}

- $\quad$ Polycrystalline Ni-Mn-Ga alloys with relatively strong $<100>$ texture axis may be obtained by rod extrusion,

- $\quad$ The calculated magnetic shear stress values and magnetocrystalline anisotropy constant are comparable to the single crystal data,

- The lowering of the twin yield stress by mechanical training was not successful for all studied alloys.

\section{Acknowledgment}

This work was financially supported by the Ministry of Science and High Education (project PBZ-KBN-115/T08/2006).

\section{References}

[1] A.A. Likhachev, K. Ullakko: Phys. Lett. A275 (2000), p. 142

[2] A. Sozinov, A.A. Likhachev, N. Lanska, K. Ullakko: Appl. Phys Lett. 80 (2002), p. 1746

[3] Advance in Shape Memory Materials - Ferromagnetic Shape memory alloys ed. by V.A. Chernenko, Trans Tech Publications LTD 2008

[4] Ferromagnetic Shape Memory Alloys, ed. by Luis Manosa, Trans Tech Publications 2008

[5] A. Böhm, S. Roth, G. Nauman, W.G. Drossel, R. Negebauer: Mater. Sci. Eng. A 481-482 (2008), p. 266

[6] Z.H. Liu, X.X. Zhang, M. Zhang, X.F. Dai, H.N. Hu, J.L. Chen, G.H. Wu: Phys. Lett. A 329 (2004), p. 214

[7] S. Besseghini, E. Villa, F. Passaretti, M. Pini, F. Bonfanti: Mat. Sci. Eng. A 378 (2004), p. 415

[8] L. Bin, W. Hua-Bin, L. Yan, L. Ji-Xuan, W.H. Lei: Trans. Nonferrous Met. Soc. China 16 (2006), p. 843

[9] H. Morawiec, T. Goryczka, A. Drdzeń, J. Lelątko, K. Prusik, Solid State Phenomena, 154 (2009) p. 133138

[10] R.C. O’Handley, D.I. Paul, S.M. Allen, M. Richard, J. Feuchtwanger, B. Peterson, R. Techapiesancharoenkij, M. Barandiarán, P. Lázpita, Mater. Sci. Eng. A 438-440 (2006) 445-449

[11] I. Kakeshita, T. Fukuda, Eur. Phys. J. Special Topic 158 (2008) p. 73-78

[12] N. Okamoto, T. Fukuda, T. Kakeshita, T. Takeuchi, Mater. Sci. Eng. A 438-440 (2006) 948-951

[13] U. Gaitzsch, M. Pötschke, S. Roth, B. Rellinghause, L. Schultz, Scr. Mat. 5 (2007) 493 